\title{
COMPARISON OF STIMULATORY EFFECT \\ OF CYTOKININS ADENINE AND UREA DERIVATIVES ON THE LEVEL OF SOME COMPONENTS IN WOLFFIA ARRHIZA (L.) WIMM. (LEMNACEAE)
}

\author{
Alicja Piotrowska, Romuald CZERPAK, \\ JoAnna AdAmowicz, Alicja BIEDRZyCKA, MARTA POTOCKA \\ University of Białystok, Institute of Biology \\ Świerkowa 20B, 15-950 Białystok, Poland \\ e-mail: alicjap@uwb.edu.pl
}

(Received: June 28. Accepted: November 2, 2004)

\begin{abstract}
The effect of cytokinins with different chemical structures, adenine-type: $N^{6}$-benzylaminopurine (BAP), $N^{6}-$ -furfurylaminopurine (FAP) and derivative of urea - 1,3-diphenylurea (DPU) applied in optimal physiological concentrations of $10^{-6}-10^{-4} \mathrm{M}$ on the mixotrophic plant Wolffia arrhiza during the period of 20 days of culture, was examined. The cytokinin highest influence on the metabolites level in $W$. arrhiza fresh weight was demonstrated in the range of concentrations $10^{-6}-10^{-5} \mathrm{M}$ between the 5th and the 10th day of culture. Among used cytokinins, the highest stimulative effect on the content of water-soluble proteins can be attributed to DPU (181\%), slightly lower to BAP (167\%) and the lowest to FAP (113\%) in comparison with the control culture (100\%). BAP was found to exert the most stimulative activity on nucleic acids accumulation (DNA+RNA) to the maximum value $(127 \%)$. FAP and DPU possessed weaker stimulative activity increasing the nucleic acid content to the level of $120 \%$ and $118 \%$, properly. The content of monosaccharides was stimulated to the highest level of $174 \%$ in FAP treated plants, to $151 \%$ in case of BAP and in case of DPU to $144 \%$. Whereas, the highest increase of the photosynthetic pigments content (chlorophyll $a$ and $b$ as well as total carotenoids) to the range of $123-146 \%$ in $W$. arrhiza culture in the presence of DPU, was observed. Under the influence of FAP the accumulation of photosynthetic pigments was stimulated less effectively to the range of 113-140\%. When the plants grew with BAP the chlorophylls and carotenoids contents increased to the lowest values of $119-131 \%$. On the other hand, the content of total carotenoids was stimulated only during the first days of culture, then between the 15th and the 20th day it was inhibited by all applied adenine and urea-type cytokinins to the value of $70 \%$. The results indicate that there is no quantitative correlation between the structure of all analysed cytokinins and their influence on the biochemical responses of $W$. arrhiza.
\end{abstract}

KEY WORDS: cytokinins, Wolffia arrhiza, biochemistry, proteins, monosaccharides, chlorophylls $a$ and $b$, total carotenoids, nucleic acids (DNA and RNA).

\section{INTRODUCTION}

Cytokinins are essential plant hormones that induce plant cell division, and they are extensively involved in plant development from seed germination to flowering and senescence (Schmülling 2002). These phytohormones are commonly present in many species of vascular plants and tissues as well as algae, fungi and phytopathogenic bacteria or bacterial symbionts e.g. Rhizobium sp. Cytokinins are synthesized mainly in root tissue, developing seeds, cambial tissue, shoot apex, and are easily distributed to a wide range of plant cells, moving trough vascular tissues (Letham 1994; Benková et al. 1999; Emery et al. 2000).

There are multiple forms of cytokinins that differ in the structure their isopentenyl side chain at $N^{6}$ position, such as isopentenyladenine (2iP), trans-zeatin (Z) and dihydrozeatin (DZ). Each of these can occur in the whole spectrum of chemical forms, including free bases, ribosides (iPR, ZR, DZR) or ribotides (e.g. zeatin riboside-5'-monophosphate) and their $N$-glucosides, which are thought to be the biologically inactive and stable compounds. A subset of cytokinins can be degraded irreversibly by cleavage of $N^{6}$ side chain by the enzyme cytokinin oxidase (Bilyeu et al. 2001; Werner et al. 2001). Numerous studies (Kakimoto 2001) confirmed that isopentenyltransferase is a key enzyme in cytokinin biosynthesis. The existence of different forms of cytokinins and enzymes that catalyze these metabolic reactions suggests that their endogenous level is tightly modulate.

The best known synthetic analogues of adenine-type cytokinins are kinetin ( $N^{6}$-furfurylaminopurine FAP) and $N^{6}$ - 
-benzylaminopurine (BAP), properly with furfuryl and aromatic ring substitutions at the $N^{6}$-position of adenine ring. However $N^{6}$-benzylaminopurine derivatives were identified as natural cytokinins in some plant species such as: Populus robusta, Pimpinella anisum, Zantedeshia and tomato (Nandi et al. 1989; Strnad 1997).

Cytokinin-like activities posses also different synthetic compounds, which were identified as derivatives of phenylurea. Among them the 1,3-diphenylurea (DPU), thidiazuron (TDZ) and $N$-2-chloro-4-pyridyl- $N$-phenylurea (CPPU) have been extensively studied. Urea-type cytokinins display qualitatively similar biological properties to adenine cytokinins in a range of bioassays. There is no evidence that any phenylurea cytokinins occur naturally in plant cells (Ricci et al. 2001).

The rootless wolfia Wolffia arrhiza (Lemnaceae) is the smallest vessel plant about $1 \mathrm{~mm}$ in length that lives in tropical and subtropical lakes and marshes (Landolt 1986). The small circular floating body of $W$. arrhiza, called a frond, is a complex of tissues with only few differentiation. The vegetative frond is covered with epidermis with numerous stomata apparatuses, underneath there is the assimilative parenchyma with numerous air spaces filled with carbon dioxide and oxygen, allowing these plants to freely move across water layers or fall down to the bottom of the reservoir (Frick and Morley 1995; Fujita et al. 1999). In unfavourable environmental conditions, e.g. low temperature, deficiency of mineral compounds, osmotic shock, unsuitable light intensity, the frond changes to a resting form, which is called a turion. This feature enables the plant to survive in a cold climate. Therefore in Polish waters it is becoming more and more popular, especially in small and shallow eutrophic reservoirs, rich in organic substances (Mical and Krotke 1999).

In changeable conditions of our environment, W. arrhiza reproduces only vegetatively through gemmation, producing descendant buds and in them pradescedant ones. This plant is very resistant to impact of various stress and toxic conditions such as: lack or excess of light, excess of ammonium ions, as well as ions of heavy metals, cyanides and other xenobiotics (Severi 1996; Mical et al. 1999).

A reasonable number of species of Lemnaceae, including in that $W$. arrhiza, in environment rich in organic substances, changes the way of feeding from photoautotrophic into mixotrophic or absolutely a heterotrophic way (Frick 1994). These plants, thanks to such properties as: possibility of mixotrophic feeding, high rate of absorption of nutrients from polluted water, quick growth, resistance to numerous toxic substances, fast multiplication in a vegetative way and plaustonic way of life, can be commonly used in biotechnology of sewage treatment especially of commune and agricultural wastewaters (Mical and Krotke 1999). Moreover, W. arrhiza may also serve as the source of food for animals because the vegetative frond contains $40-50 \%$ of protein and the turion produces large amounts of starch (Landolt 1986; Fujita et al. 1999).

The chemistry and physiology of cytokinins has been extensively investigated in typical photosynthetic plants, but their biochemical role in mixotrophic plants, of which $W$. arrhiza is the main representative, is still very limited. For this reason comparative studies regarding relationships between structure and activity of the purine-type cytokinins: $N^{6}$-benzylaminopurine (BAP) and kinetin ( $N^{6}$-furfu- rylaminopurine - FAP), varying in chemical structure of residue (properly with aromatic and furfuryl residue) at the $N^{6}$-position of adenine skeleton and urea-type (1,3-diphenylurea - DPU) in concentrations of $10^{-6}-10^{-4} \mathrm{M}$ on changes of the chosen biochemical parameters level in $W$. arrhi$z a$, were carried out. To determine the analysed organic components, the $W$. arrhiza samples were taken every 5 th day during the whole 20-day period of culture connected with the plant development cycle.

\section{MATERIALS AND METHODS}

\section{Plant material and growth conditions}

The cultivation of $W$. arrhiza was being performed for the period of 20 days under stable conditions of phytotrone, temperature at $22 \pm 1^{\circ} \mathrm{C}$, with 12 hours' long illumination by fluorescent lamps, with intensity of photosynthetic active radiation (PAR) of $50 \mu \mathrm{mol} \cdot \mathrm{m}^{-2} \cdot \mathrm{s}^{-1}$. Plants were cultivated in glass crystallisers with the capacity of 2 litres and diameter of 20 centimetres, including 1 liter of medium, covered with a polyethylene foil, completely penetrable for light. The culture of $W$. arrhiza was performed in urban water of medium richness in mineral elements and poor in organic substances. The chemical and physical characteristics of tap water Białystok are presented in Table 1. The comparative examinations regard the influence of three cytokinins: BAP ( $N^{6}$-benzylaminopurine), FAP $\left(N^{6}\right.$ furfurylaminopurine) and DPU (1,3-diphenylurea), which are chemically different, in the range of the most optimal concentrations of $10^{-6}-10^{-4} \mathrm{M}$, on the intensity of accumulation of proteins, reducing sugars, nucleic acids and photosynthetic pigments were carried out. The total content of these biological parameters was determined in $\mu \mathrm{g}$ or $\mathrm{mg}$ per g of $W$. arrhiza fresh weight.

TABLE 1. Chemical characteristics of tap water in Białystok.

\begin{tabular}{|c|c|}
\hline Analysed parameters & Tap water \\
\hline $\mathrm{pH}$ & 7.1-7.3 \\
\hline Hardness general $\left(\mathrm{mg} \mathrm{CaCO} / \mathrm{dm}^{3}\right)$ & 218.5-241.4 \\
\hline Basicity $\left(\mathrm{mval} / \mathrm{dm}^{3}\right)$ & $3.25-3.86$ \\
\hline Nitrogen ammonium $\mathrm{NH}_{4}-\mathrm{N}\left(\mathrm{mg} \mathrm{N} / \mathrm{dm}^{3}\right)$ & $0.09-0.12$ \\
\hline 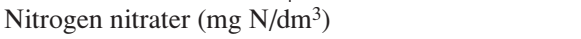 & $1.88-2.03$ \\
\hline Total Kiejdahl nitrogen $\left(\mathrm{mg} \mathrm{N} / \mathrm{dm}^{3}\right)$ & $1.97-2.15$ \\
\hline Total phosphorus $\left(\mathrm{mg} \mathrm{P} / \mathrm{dm}^{3}\right)$ & $0.02-0.04$ \\
\hline Soluble phosphorus $\left(\mathrm{mg} \mathrm{PO}_{4}{ }^{3-} / \mathrm{dm}^{3}\right)$ & $0.07-0.09$ \\
\hline Total iron $\left(\mathrm{mg} \mathrm{Fe} / \mathrm{dm}^{3}\right)$ & $0.11-0.13$ \\
\hline Chlorides $\left(\mathrm{mg} \mathrm{Cl} / \mathrm{dm}^{3}\right)$ & $12.2-14.3$ \\
\hline Organic matter $\left(\mathrm{mg} / \mathrm{dm}^{3}\right)$ & $10.8-21.4$ \\
\hline Oxidity $\left(\mathrm{mg} \mathrm{O}_{2} / \mathrm{dm}^{3}\right)$ & $4.39-4.51$ \\
\hline $\mathrm{BOD}_{5}-$ biochemical oxygen demand $\left(\mathrm{mg} \mathrm{O} / \mathrm{dm}^{3}\right)$ & $7.02-10.36$ \\
\hline $\mathrm{COD}$ - chemical oxygen demand $\left(\mathrm{mg} \mathrm{O}_{2} / \mathrm{dm}^{3}\right)$ & $9.6-22.8$ \\
\hline
\end{tabular}

\section{Determination of water - soluble proteins}

The measurement of the content of proteins soluble in water was done by homogenisation of $W$. arrhiza biomass and extracting of the fraction of water-soluble proteins overnight in $0.1 \mathrm{M} \mathrm{NaOH}$ at $4^{\circ} \mathrm{C}$. Concentration of protein was determined spectrophotometrically by the Lowry's method using Folin phenol reagent (Lowry et al. 1951) with a protein kit calibrated with bovine serum albumin as the standard. 


\section{Reducing sugars determination}

A similar preparation procedure was applied for spectrophotometric determination of monosaccharides present in the fresh weight (fr. wt) of $W$. arrhiza after plant homogenisation and extraction in ethanol during $24 \mathrm{~h}$ according to the Somogyi-Nelson's method (Hodge and Hofreiter 1962).

\section{Determination of photosynthetic pigments}

The determination of the chlorophyll $a$ and $b$ as well as total carotenoid contents followed homogenisation of $W$. arrhiza fresh weight in methanol. The absorbance of the extract was measured with a spectrophotometer at 652.4 and $665.2 \mathrm{~nm}$ for chlorophylls and $470.0 \mathrm{~nm}$ for carotenoids. The amounts of chlorophyll $a$ and $b$, as well as total carotenoids present in the methanol extract were calculated according to the equations of Wellburn (1994).

\section{Determination of nucleic acids}

The total content of nucleic acids (DNA and RNA) in plant biomass was determined spectrophotometrically, using the orcine reagent, as described by Ostrowski and Filipowicz (1980) and Rogers and Bendich (1985).

An UV/Vis spectrophotometer (SHIMADZU type 1201, Japan) was used for all measurements.

\section{Replication and statistical analysis}

Each treatment consisted of five replicates and each experiment was carried out at least twice at different times. A minitab statistical package was used to carry out the oneway ANOVA. Significance was determined using t-tests and LSD values based on the ANOVA data.

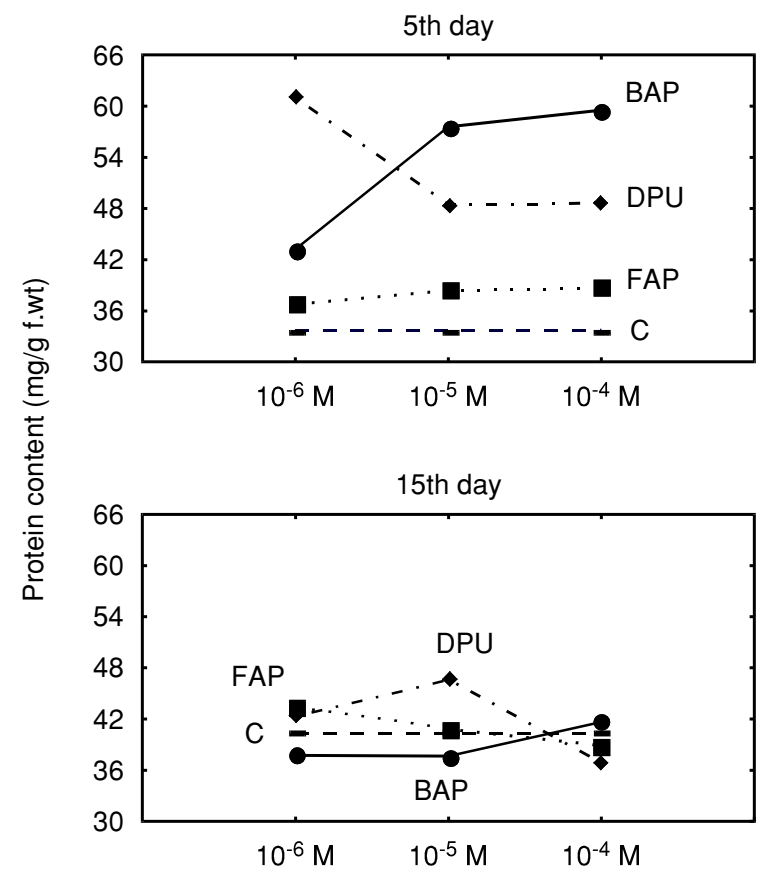

\section{RESULTS}

The results of our examinations regarding the effect of structurally different cytokinins: $N^{6}$-benzylaminopurine (BAP), $N^{6}$-furfurylaminopurine (FAP), commonly known as kinetin and 1,3-diphenylurea (DPU), on the contents of essential metabolites in Wolffia arrhiza growing on tap water during the period of 20 days of culture, are presented in Figs 1-6.

The content of water-soluble proteins fraction in the fresh weight was the strongest stimulated at the beginning of the $W$. arrhiza culture under the influence of the optimal physiological range of cytokinins concentrations from $10^{-6}$ to $10^{-4} \mathrm{M}$ (Fig. 1). It was found that on the 5th day of culture the accumulation of water-soluble proteins reached the maximum level of $181 \%$ under the influence of $10^{-6}$ M DPU, a slightly lower level in the range of $167-161 \%$ under the influence of $10^{-5-} 10^{-4} \mathrm{M}$ BAP properly, and the lowest level of merely $108-113 \%$ in the presence in the media of $10^{-4} \mathrm{M}$ FAP in comparison with the control culture without the exogenous cytokinins $(100 \%)$. On the other hand, on the 15th day, and especially on the 20th day, when $W$. arrhiza culture is ageing, noticed was a weak inhibitory effect of all the analysed cytokinins on water-soluble proteins contents ranging from several to a dozen or so percent, particularly the most clearly under the BAP, little weaker under DPU and the weakest under FAP influence.

The stimulation of the total content of nucleic acids (DNA+RNA) was observed during the whole 20 day period of $W$. arrhiza culture after the external addition of all cytokinins to the media (Fig. 2). The highest concentration of nucleic acids in plant fresh weight was found on the 15 th day of experiment. Particularly, the content of nucleic acids increased to the maximum level of $127 \%$ in the $10^{-5}$

Cytokinin concentration (M)
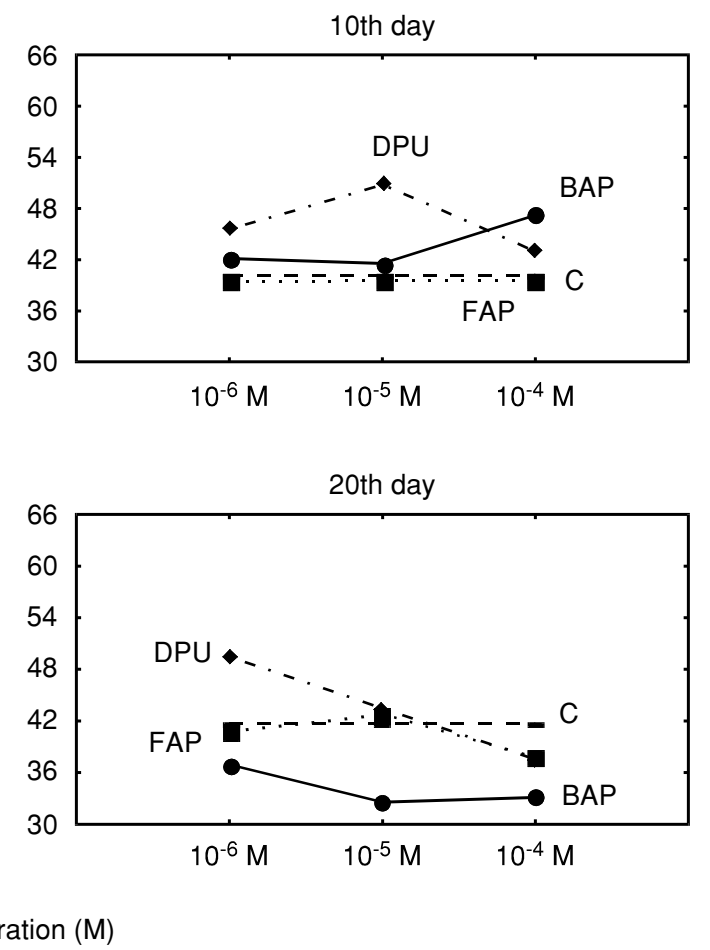

Fig. 1. The effect of cytokinins (BAP $-N^{6}$-benzylaminopurine, FAP $-N^{6}$-furfurylaminopurine and DPU $-1,3$-diphenylurea) on the water-soluble proteins content in Wolffia arrhiza between the 5th and the 20th day of culture ( $\mathrm{C}-$ control culture) $(\mathrm{SE}<5 \%)$. 

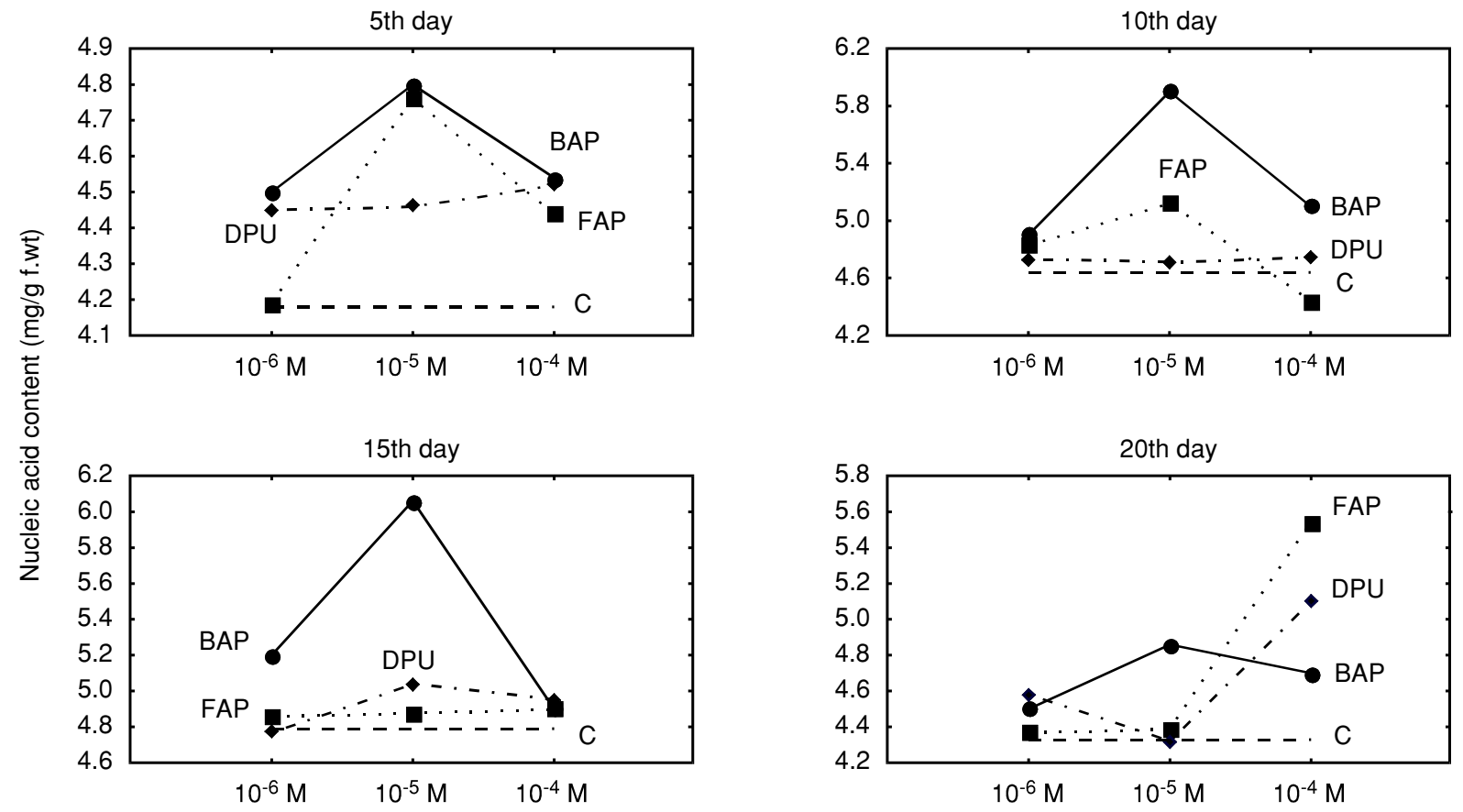

Cytokinin concentration (M)

Fig. 2. The effect of cytokinins (BAP $-N^{6}$-benzylaminopurine, FAP $-N^{6}$-furfurylaminopurine and DPU $-1,3$-diphenylurea) on the nucleic acids content in Wolffia arrhiza between the 5 th and the 20 th day of culture (C - control culture) $(\mathrm{SE}<5 \%)$.
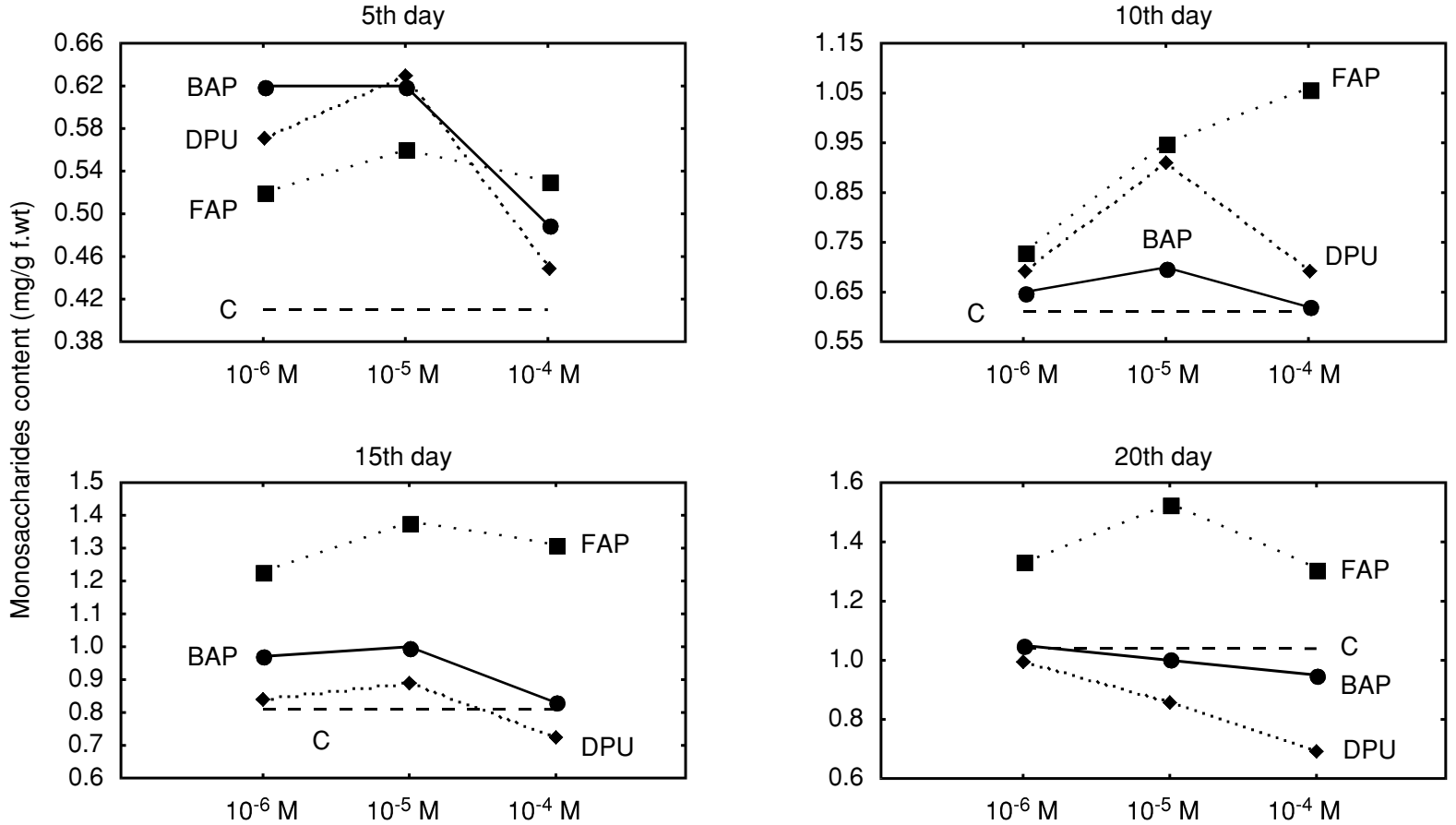

Cytokinin concentration (M)

Fig. 3. The effect of cytokinins (BAP $-N^{6}$-benzylaminopurine, FAP $-N^{6}$-furfurylaminopurine and DPU - 1,3-diphenylurea) on the monosaccharides content in Wolffia arrhiza between the 5th and the 20th day of culture (C - control culture) $(\mathrm{SE}<5 \%)$.

M BAP - treated plant, to $120 \%$ in case of $10^{-4}$ M FAP and to $118 \%$ in case of $10^{-5} \mathrm{M}$ DPU on the 15 th day of cultivation, in regard to the control culture (100\%). However, on the 5th day, and particularly on the 20th day of culture, the insignificant stimulation of nucleic acids content to the level of several percent over control culture under the influence of $10^{-4} \mathrm{M}$ FAP, DPU and $10^{-5} \mathrm{M}$ BAP, was recorded.
The results presented in Fig. 3 show that accumulation of the monosaccharides in the control increased progressively during the whole 20-day period of $W$. arrhiza cultivation. However, the content of monosaccharides in the fresh weight, was most stimulated under the influence of all cytokinins in the range of concentrations $10^{-6}-10^{-5} \mathrm{M}$. On the 10th day of cultivation the application of $10^{-4}$ and $10^{-5} \mathrm{M}$ of 

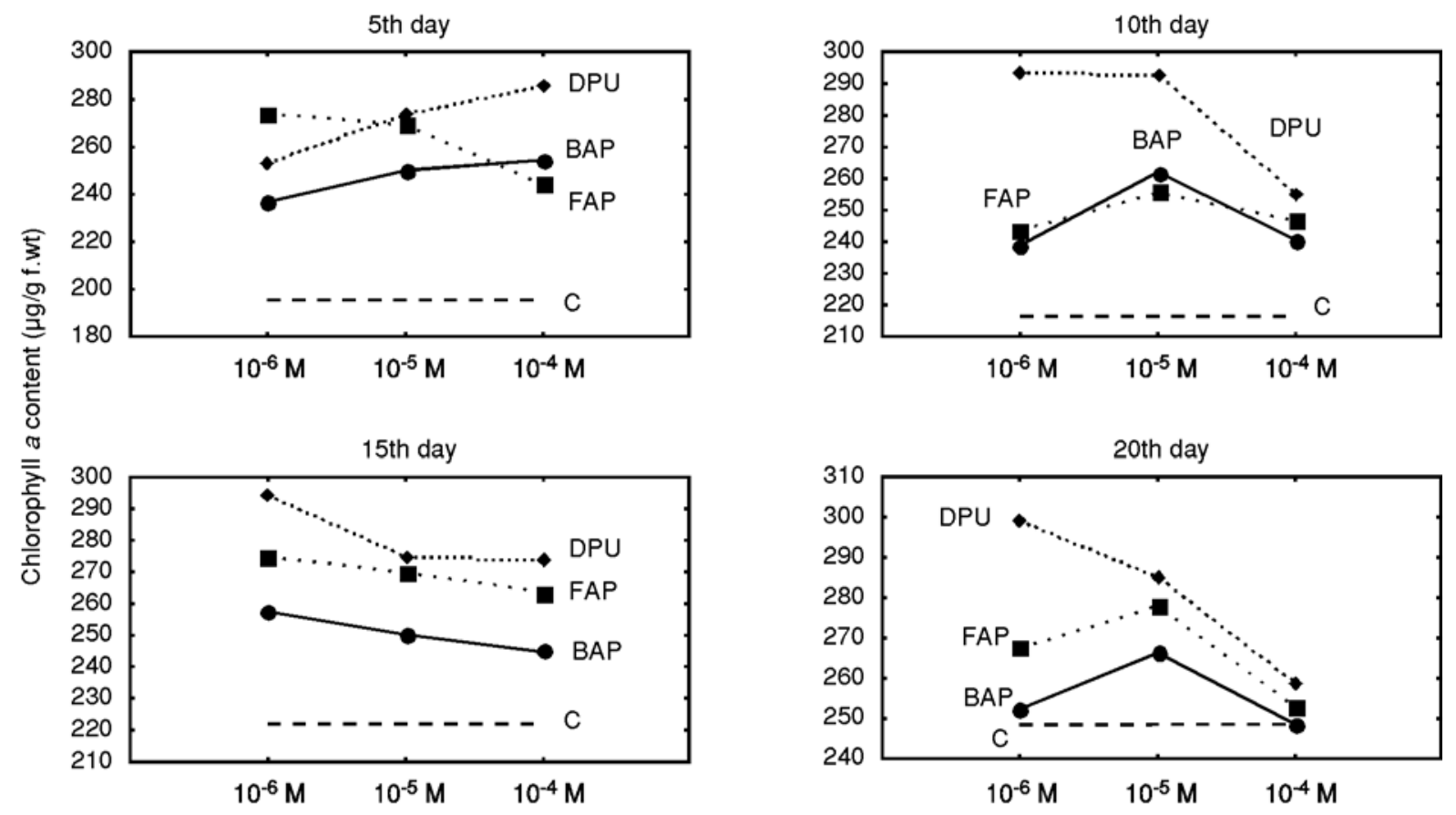

Cytokinin concentration (M)

Fig. 4. The effect of cytokinins (BAP $-N^{6}$-benzylaminopurine, FAP $-N^{6}$-furfurylaminopurine and DPU $-1,3$-diphenylurea) on the chlorophyll $a$ content in Wolffia arrhiza between the 5 th and the 20th day of culture (C - control culture) $(\mathrm{SE}<5 \%)$.
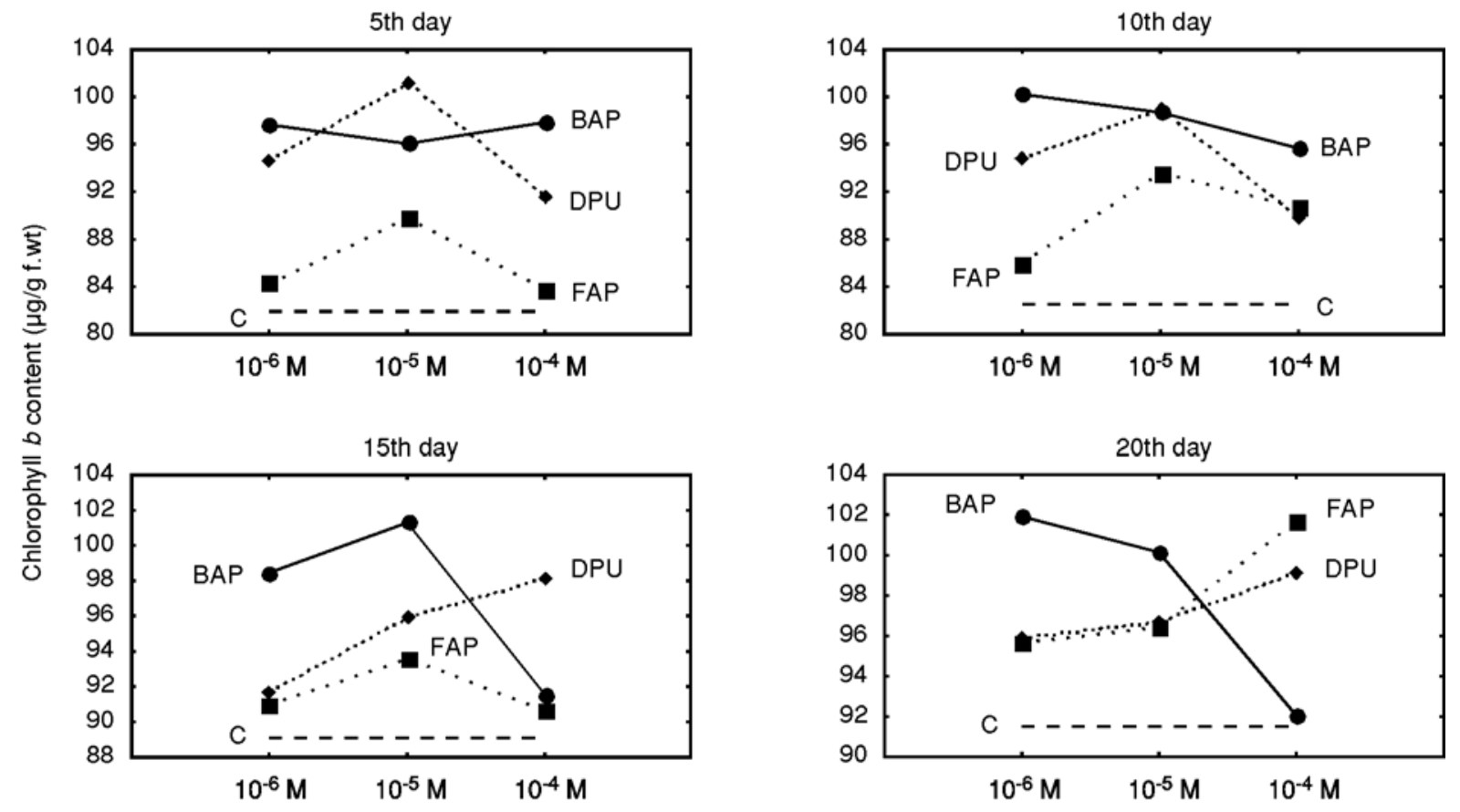

Cytokinin concentration (M)

Fig. 5. The effect of cytokinins (BAP $-N^{6}$-benzylaminopurine, FAP $-N^{6}$-furfurylaminopurine and DPU $-1,3$-diphenylurea) on the chlorophyll $b$ content in Wolffia arrhiza between the 5th and the 20th day of culture (C - control culture) $(\mathrm{SE}<5 \%)$.

FAP has resulted in the highest increase of monosaccharides accumulation to maximum values of $174 \%$ and $170 \%$, properly. It was observed that FAP showed a stimulatory effect on sugar content during the whole period of $W$. arrhiza cultivation, particularly between the 5 th and the 10 th day of cultivation. Under the influence of $10^{-6}-10^{-4} \mathrm{M}$ DPU and BAP the content of monosaccharides was stimulated to a lower level of $144-151 \%$, when compared with the control $(100 \%)$. On the other hand on the 20th day of culture DPU and BAP acted as weak inhibitors of monosaccharides accumulation and decrease of content of this biochemical parameter $1-2 \%$ below the control, was noticed.

Fig. 4 presents that the content of chlorophyll $a$ in $W$. arrhiza biomass was most stimulated on the 5th day of cultu- 

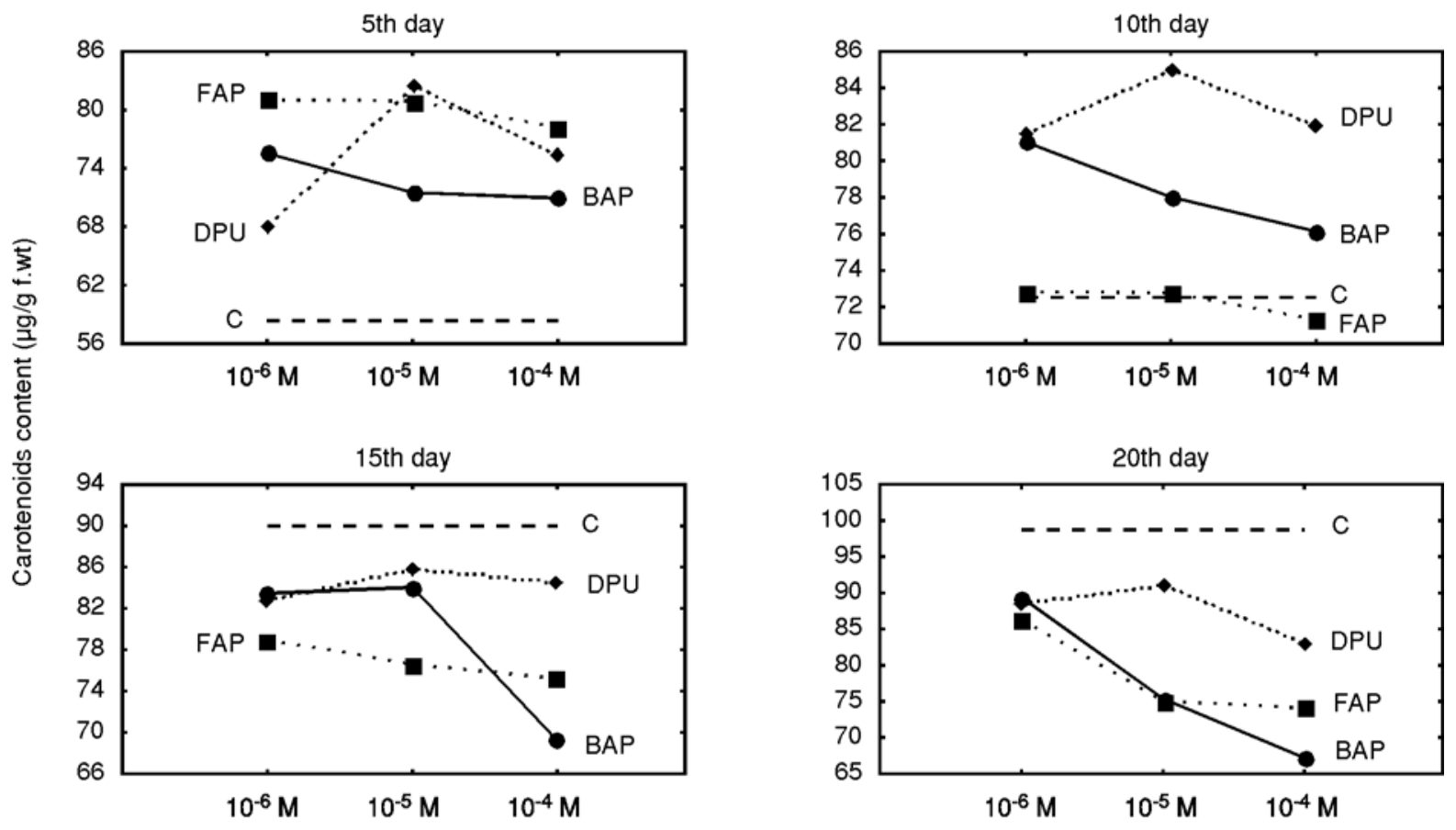

Cytokinin concentration (M)

Fig. 6. The effect of cytokinins (BAP $-N^{6}$-benzylaminopurine, FAP $-N^{6}$-furfurylaminopurine and DPU - 1,3-diphenylurea) on the carotenoids content in Wolffia arrhiza between the 5 th and the 20th day of culture $(\mathrm{C}-$ control culture $)(\mathrm{SE}<5 \%)$.

re under the influence of DPU and BAP in the range of concentrations $10^{-4}-10^{-5} \mathrm{M}$, reaching maximum values of $131-146 \%$ in comparison with the control (100\%). FAP in the range of concentration $10^{-6}-10^{-5} \mathrm{M}$ stimulated the increase of the chlorophyll $a$ amounts to a lower level of $140 \%$, compared with the control. Between the 15th and the 20th day of cultivation the stimulatory effect of all the analysed cytokinins, except of $10^{-6} \mathrm{M}$ DPU, on accumulation of chlorophyll $a$ was reduced to the same level observed in the control culture (approximately 100\%).

The analysed cytokinins had a quite weaker influence on the accumulation of chlorophyll $b$ in biomass of $W$. arrhiza (Fig. 5), in comparison with the amount of chlorophyll $a$. It was found that the treatment of $W$. arrhiza culture with DPU and BAP caused an increase of the content of chlorophyll $b$ to the maximum range of $117-123 \%$ and to 119 $-122 \%$ properly, between the 5 th and the 10th day of experiment. In turn, FAP was the most active in the concentration of $10^{-5} \mathrm{M}$ and increased the content of chlorophyll $b$ to the values in the range of $110-113 \%$ also between the 5th and the 10th day of cultivation regarding to the control $(100 \%)$.

The successive increase of total carotenoids level in the control culture is observed during the whole period of $W$. arrhiza cultivation. However, carotenoids content was the most clearly stimulated under the influence of $10^{-5} \mathrm{M}$ DPU between the 5th and the 10th day and reached the optimal level of $140 \%$ (Fig. 6). Whereas, between the 15th and 20th day of culture the carotenoids content in DPU-treated plant was inhibited to the minimum value of $83 \%$ in relation to the control (100\%). The addition of FAP in concentrations of within $10^{-6}-10^{-5} \mathrm{M}$ resulted in a lower stimulative effect, inducing the increase of carotenoids content to the value of $116-130 \%$ between the 5th and 10th day of cultivation. However, in the ageing W. arrhiza culture, be- tween the 15th and the 20th day, FAP could inhibit the accumulation of carotenoids to $70-93 \%$ against the control $(100 \%)$. In turn, BAP showed the most stimulative activity in concentrations of $10^{-6} \mathrm{M}$ and $10^{-5} \mathrm{M}$ only on the 5th day of experiment, promoting an increase of the total carotenoids content to the level of $138 \%$. On the other hand, the decrease of the content of carotenoids to the control level (ca. $100 \%$ ) on the 10th day and to the value of $75 \%$ between the 15 th and the 20th day of culture under the influence of $10^{-4} \mathrm{M}$ BAP, was observed.

\section{DISCUSSION}

Current information on activity of cytokinins both derivatives of adenine and urea in mixotrophic vessel plants are incomplete and fragmentary. Therefore our examinations focused on the effect of chemically different cytokinins: $N^{6}$-benzylaminopurine (aromatic cytokinin), $N^{6}$-furfurylamninopurine (heterocyclic cytokinin) and 1,3-diphenylurea (urea cytokinin) on the biochemical activity of $W$. arrhiza (Lemnaceae), which is more and more often used in urban and agricultural sewage treatment plants. The results reported in this paper show that $W$. arrhiza reacts much weaker to applied exogenous cytokinins in comparison with typical photosynthetic vessel plants and algae from Chlorophyta (Czerpak 1990; Czerpak and Bajguz 1997; Czerpak et al. 1999).

Generally, the stimulating effect of cytokinins on the content of essential metabolites in W. arrhiza was demonstrated in the range of concentrations $10^{-6}-10^{-5} \mathrm{M}$ between the 5th and the 10th day of culture. After 15-20 days of all cytokinins treatment in case of monosaccharides, proteins and carotenoids contents these phytohormones were found to have a weak inhibitory activity. They probably inhibit 
conjugated proteins and polysaccharides degradation and carotenoids accumulation, what is the major mechanism of delaying senescence. Our observations are supported by other examinations, where high concentration of BAP had a high inhibitory effect on the growth of other plant from Lemnaceae (Lemna minor) (Hurtubise et al. 1992). This suggests that exogenously applied adenine cytokinins (FAP and BAP) are probably converted to nucleotides, nucleosides or glycoside conjugates, which play a key role in cytokinin protection from degradation and reversible or irreversible inactivation (Van Staden and Drewes 1991).

From among the used cytokinins $10^{-6} \mathrm{M}$ DPU is considered to have the most stimulating influence on the content of water-soluble proteins $(181 \%)$ and photosynthetic pigments: chlorophyll $a(146 \%)$ and $b(123 \%)$ as well as total carotenoids $(142 \%)$ in fresh mass of $W$. arrhiza on the 5th day of culture in relation to the control $(100 \%)$. The greater quantitative effect of DPU in $W$. arrhiza culture might be explained by more penetration and metabolic properties or, alternatively, by higher target sensitivity. In many tested plants, phenylurea cytokinins demonstrated better stimulative features than adenine cytokinins such as: zeatin, BAP, FAP or $2 \mathrm{iP}$ in the induction of embryo growth, the apical dominance release, the increase of shoot number and the accumulation of fresh and dry weight (Sansberro et al. 1998). Phenylureas possess also a higher influence than adenine-type cytokinins in induction of growth, formation of callus in tobacco, pea, ginseng and datura and stimulation of shoot formation of tobacco, azalea, petunia, mulberry and torenia and initiation of potato tubers (Kapchina-Toteva et al. 2000; Kefi et al. 2000).

The greater effectiveness of DPU over adenine cytokinins (BAP and FAP) in stimulation of the content of watersoluble proteins and photosynthetic pigments in W. arrhiza may be explained by its chemical stability and resistance to conjugation process in contrast to adenine cytokinins (Letham 1994). Urea-type cytokinins have an inhibitory effect on cytokinin oxidase activity, which catalyze the irreversible degradation of $N^{6}$-substituted purine cytokinins in plants (Bilyeu et al. 2001; Werner et al. 2001). Therefore DPU may precisely regulate the level of endogenous cytokinins and indirect induce the biochemical response of $W$. arrhiza to the phytohormones treatment. In addition, conversion of nucleotides to nucleosides and promotion of adenine cytokinin synthesis is also stimulated by urea-type cytokinins (Ricci et al. 2001).

The treatment of $W$. arrhiza culture with BAP and FAP has also stimulated the content of water-soluble proteins and photosynthetic pigments, but less effectively in comparison with DPU. Our results are concordant with earlier reports, demonstrating that the content and the activity of numerous proteins is stimulated by cytokinins, e.g. light-harvesting chlorophyll $a / b$ - binding protein or enzymes involved in Calvin cycle in Lemna minor (Hurtubise et al. 1992; Letham 1994; Che et al. 2002). Cytokinins inhibit the degradation of chlorophylls and photosynthetic proteins as well as chlorophyllase activity, what is the major mechanism of delaying plant senescence and increase the chlorophylls content, the ratio of chlorophyll $a / b$ in the final functional photosynthetic membranes, anthocyjannins, betacyjannins and protochlorophyllide content in vascular plant species and in the green alga Chlorella pyrenoidosa (Czerpak 1990; Czerpak and Bajguz 1997; Genkov et al. 1997).
On the other hand, BAP most effectively stimulated the content of total nucleic acids $(127 \%)$ in $W$. arrhiza in relation to FAP (120\%) and DPU (118\%). It is widely accepted that BAP, as well as other adenine-type cytokinins regulate the activity of some genes and stimulate transcription initiation. The increase of various mRNAs accumulation involved in plant growth, development and greening (e.g. chloroplast development and differentiation, NADH-cytochrome reductase, enzymes responsible for starch synthesis, RUBP small subunit gene, cell cycle genes) was reported in many plant species as well as Lemna sp. (Kimura 2001; Che et al. 2002; Schmülling 2002; Rashotte et al. 2003; Werner et al. 2001).

From among cytokinins, kinetin (FAP), in the range of concentration $10^{-5}-10^{-4} \mathrm{M}$ on the 10 th-15th days of $W$. arrhiza cultivation, exhibited the most dramatic rise in monosaccharides content (174\%) than it was observed in case of DPU and BAP treatment. In earlier research it was demonstrated that biochemical activity of the FAP within the optimum concentration of $10^{-4}-10^{-5} \mathrm{M}$ in the cultivation of alga $C$. pyrenoidosa is slightly higher than other cytokinins, such as BAP. The $10^{-4} \mathrm{M}$ FAP, as compared to BAP, stronger induced the increase of the content of aldohexoses, most intensively between the 10th and the 20th day of algae cultivation to the range of values of $185.5-249.7 \%$ (Czerpak 1990; Czerpak et al. 1999). Cytokinins also induce the activity of extracellular invertases activity in Nicotiana tabacum, what increases the endogenous concentration of osmothically active monosaccharides. This mechanism delays senescence and causes nutrient mobilisation (Lara et al. 2004). The high activity of FAP in other species of the Lemnaceae family is confirmed by results which demonstrated that FAP reduced the toxic influence of aluminium on metabolism, and lipid peroxidation acted as a strong antioxidant (Severi 1996).

The analysis indicates that there is no qualitative correlation between the different structure of phenylurea or adenine cytokinins and their influence on the biochemical responses of $W$. arrhiza. Each of the analysed cytokinins have had a different stimulative effect on the content of biochemical parameters in $W$. arrhiza. We can conclude that 1,3-diphenylurea, a derivative of urea's with cytokinin activity acted differently from typical adenine cytokinins, slightly effectively promoting the increase of the majority of metabolites (proteins and photosynthetic pigments) levels. Among tested adenine cytokinins, the presence of the aromatic group (in case of BAP) or analogical furfuryl group (in case of FAP) located by the nitrogen from the amine group connected with atom C-6 of the adenine ring didn't change significantly their biological properties in the mixotrophic plant $W$. arrhiza. By comparison of our results with literature data regarding other typical photosynthetic plant species, it was found that BAP exerted a simulative effect on $W$. arrhiza metabolism in a manner qualitatively similar to FAP.

\section{LITERATURE CITED}

BENKOVÁ E., WITTERS E., VAN DONGEN W., KOLÁŘ J., MOTYKA V., BRZOBOCHATY B., VAN ONCKELEN H.A., MACHÁČKOWÁ I. 1999. Cytokinins in tobacco and wheat chloroplasts. Occurrence and changes due to light/dark treatment. Plant Physiol., 121: 245-251. 
BILYEU K.D., COLE J.L., LASKEY J.G., RICKHOF W.R., ESPARZA T.J. 2001. Molecular and biochemical characterization of a cytokinin oxidase from Zea mays. Plant Physiol., 125: 378-386.

CHE P., GINGERICH D.J., LALL S., HOWELL S.H. 2002. Global and hormone induced gene expression changes during shoot development in Arabidopsis. Plant Cell, 14: 2771-2785.

CZERPAK R. 1990. Pobudzający wpływ auksyn i cytokin na wzrost i zawartość niektórych metabolitów u Chlorella pyrenoidosa. Publ. Sect. of Warsaw Univ., Branch in Białystok, p. 225. (in Polish)

CZERPAK R., BAJGUZ A. 1997. Stimulatory effect of auxins and cytokinins on carotenes, with differential effects on xanthophylls in the green alga Chlorella pyrenoidosa Chick. Acta Soc. Bot. Pol., 66: 41-46.

CZERPAK R., KROTKE A., MICAL A.H. 1999. Comparison of stimulatory effect of auxins and cytokinins on protein, saccharides and chlorophylls content in Chlorella pyrenoidosa Chick. Pol. Arch. Hydrobiol., 46: 71-82.

EMERY R.J.N., MA Q., ATKINS C.A. 2000. The forms and the sources of cytokinins in developing white lupine seeds and fruits. Plant Physiol., 123: 193-1604.

FRICK H. 1994. Heterotrophy in Lemnaceae. J. Plant Physiol., 144: 189-193.

FRICK H., MORLEY K. 1995. Metabolism of lactose by Lemna minor L. (Duckweed). Proc. Biochem., 30: 57-62.

FUJITA M., KAZUHIRO M., KODERA T. 1999. Nutrient removal and starch production through cultivation of Wolffia arrhi$z a$. J. Biosci. Bioeng., 87: 194-198.

GENKOV T., TSANEVA P., IVANOVA I. 1997. Effect of cytokinins on photosynthetic pigments and chlorophyllase activity in vitro cultures of auxiliary buds of Dianthus caryophyllus L. J. Plant Growth. Reg., 16: 169-172.

HODGE J.E., HOFREITER B.T. 1962. Somogyi micro copper method. In: Whistler R.L., Wolfrom M.L. (eds). Methods in Carbohydrate Chemistry. Acad. Press, New York.Vol. 1: 383-386.

HURTUBISE Y., PROTEAU L., GRENIER G. 1992. Effects of benzyladenine on $\left[\mathrm{U}-{ }^{14} \mathrm{C}\right]$ acetate incorporation into lipids of Lemna minor. Phytochemistry, 31: 3827-3833.

KAKIMOTO T. 2001. Identification of plant cytokinin biosynthetic enzymes as dimethylallyl diphosphate: ATP/ADP isopentenyltransferases. Plant Cell Physiol., 42: 677-685.

KAPCHINA-TOTEVA V., VAN TELGEN H.J., YAKIMOVA E. 2000. Role of phenylurea cytokinin CPPU in apical dominance release in in vitro cultured Rosa hybrida L. J. Plant Growth Regul., 19: 232-237.

KEFI S., PAVLISTA A.D., READ P.E., KACHMAN S.D. 2000. Comparison of thidiazuron and two nitroguanidines to kinetin on potato micotuberization in vitro under short and long days. J. Plant Growth Regul., 19: 429-436.

KIMURA T., NAKANO T., TAKI N., ISHIKAWA M., ASAMI T., YOSHIDA S. 2001. Cytokinin-induced gene expression in cultured green cells of Nicotiana tabacum identified by fluorescent differential display. Biosci. Biotechnol. Biochem., 65: 1275-1283.
LANDOLT E. 1986. The family Lemnaceae - a monographic study. Vol. 1. Veröff. Geobot. Inst. ETH, Stiftung Rübel, Zürich.

LARA M.E.B., GARCIA M.C.G., FATIMA T., EHNEß R., LEE T.K., PROELS R., TANNER W., ROITSCH T. 2004. Extracellular invertase is essential component of cytokinin-mediated delay of senescence. Plant Cell, 15: 2532-2550.

LETHAM D.S. 1994. Cytokinins as phytohormones: sites of biosynthesis, translocation and function of translocated cytokinin. In: MOK D.W.S., MOK M.C. (eds). Cytokinins, chemistry, activity and function. CRC Press, Boca Ration, FL, pp 127$-137$.

LOWRY O.H., ROSEBROUGH N.J., FARR A.L., RANDALL R.J. 1951. Protein measurement with the Folin phenol reagent. J. Biol. Chem., 193: 265-275.

MICAL A.H., KROTKE A. 1999. Wolffia arrhiza (L.) - small but strong. Acta. Hydrobiol. (suppl.) 41: 165-170.

MICAL A.H., KROTKE A., SULEWSKA A. 1999. Physiological and metabolic feature of Wolffia arrhiza and her practical advantage. Fol. Univ. Agric. Stetin, 77: 263-266.

NANDI S.K., LETHAM D.S., PALNI L.M.S., WONG O.C., SUMMONS R.E. 1989. 6-Benzylaminopurine and its glycosides as naturally occurring cytokinins. Plant Sci., 61: 189-196.

OSTROWSKI W., FILIPOWICZ B. (ed.) 1980. Ćwiczenia z chemii ogólnej i fizjologicznej. PZWL, Warsaw. (in Polish)

RASHOTTE A., CARSON S.D.B., TO J.P.C., KIEBER J.J. 2003. Expression profiling of cytokinin action in Arabidopsis. Plant Physiol., 132: 1998-2011.

RICCI A., CARRA A., TORELLI A., MAGGIALI C.A., MORINI G., BRANCA C. 2001. Cytokinin-like activity of $N, N^{\prime}$-diphenylureas. Plant Sci., 160: 1055-1065.

ROGERS S.O., BENDICH A.J. 1985. Extraction of DNA from milligram amounts of fresh, herbarium and mummified plant tissue. Plant Mol. Biol., 5: 69-76.

SANSBERRO P.A., REY H.Y., MROGINSKI L.A., COLLAVINO M.M. 1998. In vitro culture of rudimentary embryos of Ilex paraguariensis: responses to exogenous cytokinin. J. Plant Regul., 17: 101-105.

SCHMÜLLING T. 2002. New insights into the functions of cytokinins in plant developments. J. Plant Growth. Regul., 21: 40$-49$.

SEVERI A. 1996. Aluminium toxicity in Lemna minor L.: effects of citrate and kinetin. Environ. Experim. Bot., 37: 53-61.

STRNAD M. 1997. The aromatic cytokinins. Physiol. Plant., 101: 674-688.

VAN STADENJ. DREWES F.E. 1991. The biological activity of cytokinin derivatives in the soybean callus bioassay. Plant Growth Regul., 10: 109-115.

WELLBURN A.R. 1994. The spectral determination of chlorophyll $a$ and $b$, as well as total carotenoids, using various solvents with spectrophotometers of different resolution. J. Plant Physiol., 144: 307-313.

WERNER T., MOTYKA V., STRNAD M., SCHMÜLLING T. 2001. Regulation of plant growth by cytokinin. PNAS, 98: 10487-10492. 